\title{
Short communication: Association analysis of diacylglycerol acyltransferase (DGAT1) mutation on chromosome 14 for milk yield and composition traits, somatic cell score, and coagulation properties in Holstein bulls
}

\author{
T. Bobbo, ${ }^{*}$ F. Tiezzi, $†$ M. Penasa, ${ }^{* 1}$ M. De Marchi, ${ }^{*}$ and M. Cassandro* \\ *Department of Agronomy, Food, Natural Resources, Animals and Environment (DAFNAE), University of Padova, 35020 Legnaro, Padova, Italy \\ †Department of Animal Science, North Carolina State University, Raleigh 27695
}

\begin{abstract}
The aim of the present study was to determine the allele frequencies of the diacylglycerol acyltransferase (DGAT1) K232A mutation in Italian Holstein bulls and to estimate the effect of the mutation on milk yield, composition, somatic cell score, and coagulation traits (rennet coagulation time and curd firmness). For this purpose, 349 Italian Holstein bulls were genotyped for the DGAT1 mutation on chromosome 14. Association analysis was performed by regressing the number of copies for the $K$ allele on the deregressed estimated breeding value of the individual. Breeding values were calculated using field data routinely collected in Northeast Italy. The frequencies of the $A A, K A$, and $K K$ genotypes were $59.6,32.1$, and $8.3 \%$, respectively, and the minor allele frequency ( $K$ variant) was $24.7 \%$. The $K$ allele was significantly associated with greater fat yield and fat, protein, and casein percentages and with reduced protein:fat ratio. The association between the DGAT1 mutation and somatic cell score was not significant, whereas a favorable association between presence of the $K$ allele and milk coagulation properties was found. Results from the present study confirmed the effect of the diallelic DGAT1 polymorphism K232A on milk production traits and, for the first time, provided evidence that this mutation also affects milk coagulation properties in the Italian Holstein breed.
\end{abstract}

Key words: coagulation trait, diacylglycerol acyltransferase, dairy cattle, milk composition

\section{Short Communication}

The use of genomic information for animal selection is a valuable tool in genetic improvement programs (Miglior et al., 2017). Association studies using a candidate-gene approach are common methods for

Received February 2, 2018.

Accepted May 23, 2018.

${ }^{1}$ Corresponding author: mauro.penasa@unipd.it exploring the relationship between allelic variation in specific relevant regions of the genome and the underlying phenotypes of interest. In recent decades, several genes affecting economically important traits in livestock species have been localized within QTL dispersed across the genome. In cattle breeds, the diacylglycerol acyltransferase (DGAT1), a candidate gene located on the centromeric region of Bos taurus autosome 14, encodes acyl coenzyme A:diacylglycerol acyltransferase, a protein involved in fat metabolism (Grisart et al., 2002; Winter et al., 2002). Polymorphisms in the DGAT1 gene, resulting from a lysine to alanine substitution at position 232 (K232A mutation), have been associated with differences in the kinetics of the enzymes encoded by the 2 allelic variants (Grisart et al., 2004). In particular, Grisart et al. (2004) demonstrated that the lysine variant, which represents the "wild type" and is defined as $K$ allele, is characterized by a higher $\mathrm{V}_{\max }$ (maximum rate of reaction) of the enzyme in synthesizing triglycerides compared with the alanine variant (A allele), thus increasing the fat percentage in the milk of the animal.

The distribution of the allele frequencies of the DGAT1 K232A mutation has been evaluated in different Holstein populations and other dairy cattle breeds, and the effects of the DAGT1 polymorphisms on milk production traits have been widely investigated (Gautier et al., 2007; Barbosa da Silva et al., 2010; Manga and Ǩ́ha, 2011). In particular, the lysine variant has been associated with increased fat yield and fat and protein percentages, whereas the alanine variant has been associated with increased milk and protein yield (Spelman et al., 2002; Näslund et al., 2008). Nevertheless, the diallelic DGAT1 effect on milk production traits also could be partially explained by the presence of multiple alleles at the DGAT1 locus or other mutations in closely related genes (Bennewitz et al., 2004; Kühn et al., 2004). Furthermore, the DGAT1 gene may also affect nonproduction traits such as carcass fatness (Thaller et al., 2003), conformation, reproduction (Kaupe et al., 2007), body energy, and blood metabolic 
traits (Oikonomou et al., 2009). However, the effect of DGAT1 on nonproduction traits is still controversial; in fact, Berry et al. (2010) reported no association between the K232A mutation and fertility, survival, calving performance, and conformation traits, with the only exception of rump width.

To date, the effect of DGAT1 mutation on milk quality and some nonproduction traits has been evaluated, whereas the effect of this gene on milk technological traits such as milk coagulation properties (MCP) has not yet been investigated. These traits are relevant in many countries because a large amount of the produced milk is used to manufacture cheese, and their effect on cheese yield and quality has been demonstrated (Pretto et al., 2013; Visentin et al., 2017). Therefore, the aim of the present study was to determine the allele frequencies of the DGAT1 K232A mutation in Italian Holstein bulls and to estimate the effect of the 2 allelic variants on milk yield, milk composition, SCS, and MCP.

For the present study, 349 Italian Holstein sires were genotyped for the DGAT1 mutation on chromosome 14 following the methodologies reported in Conte et al. (2010) and Viale et al. (2017). Briefly, semen samples were collected and DNA extraction was performed using the DNeasy blood and tissue kit (catalog no. 69506; Qiagen, Valencia, CA). The Qubit System (Invitrogen, Carlsbad, CA) was used for DNA quantification, and DNA integrity was assessed by $1 \%$ agarose gel electrophoresis. Genotyping was performed with the Illumina GoldenGate Assay (Illumina Inc., San Diego, CA), and the GeneCall software (Illumina) with a GCscore threshold of 0.25 was used for automatic allele calling.

Once genotype and allele frequencies were determined, a chi-squared test was used to examine whether the population deviated from Hardy-Weinberg equilibrium using the $\mathrm{R}$ package HardyWeinberg (Graffelman, 2015). Approximate standard errors of allele frequencies were calculated as in Banos et al. (2008) by the square root of $P(1-P) / n$, where $P=$ allelic frequency and $n=$ number of bulls.

Association analysis was performed by regressing the number of copies for the $K$ allele on the deregressed estimated breeding value (dEBV) of the individual. Breeding values were calculated from field data routinely collected in the Veneto region of Northeast Italy. Traits included milk yield; fat, protein, and casein percentages; SCC; and MCP [i.e., rennet coagulation time (RCT; min) and curd firmness 30 min after rennet addition $\left.\left(\mathbf{a}_{\mathbf{3 0}} ; \mathbf{m m}\right)\right]$. Fat yield, protein yield, casein yield, protein:fat ratio, and casein:protein ratio were derived from previous field traits. Mid-infrared spectroscopy calibration models for routine prediction of MCP (De Marchi et al., 2012) were installed on Milko-
Scan FT6000 (Foss Electric A/S, Hillerød, Denmark) of the laboratory of the Breeders Association of Veneto Region (Padova, Italy). Coefficients of determination in cross-validation were 0.76 for RCT and 0.70 for $\mathrm{a}_{30}$ (De Marchi et al., 2012), suggesting high correlations between measured and predicted traits $(0.87$ and 0.83 , respectively). Somatic cell count was log-transformed to SCS according to Wiggans and Shook (1987). Data editing and statistical model used for EBV calculation were the same as reported by Tiezzi et al. (2013) but applied to data collected from September 2011 to June 2017. After editing, 1,309,884 observations from 156,391 cows (daughters of 6,544 bulls) and 1,479 herds were available. The dEBV were obtained following Garrick et al. (2009), and only individuals with dEBV reliability greater than 0.20 for all traits considered were used in the analysis. The model used for association analysis was a single marker regression with the number of copies of the $K$ allele as fixed effect:

$$
\mathrm{y}_{\mathrm{ij}}=\mathbf{X} \mathbf{b}_{\mathrm{i}}+\mathbf{Z}_{\mathrm{j}}+\frac{\mathrm{e}_{\mathrm{ij}}}{\mathrm{w}_{\mathrm{ij}}},
$$

where $\mathrm{y}_{\mathrm{ij}}$ is the pseudo-phenotype (dEBV) for the jth individual, $\mathbf{b}_{i}$ is a vector of solutions for the population mean and average allele substitution (fixed) effect, $a_{j}$ is the animal additive polygenic effect, $\mathrm{e}_{\mathrm{ij}}$ is the residual, $\mathrm{w}_{\mathrm{ij}}$ is the weight of the $\mathrm{y}_{\mathrm{ij}} \mathrm{dEBV}, \mathbf{X}$ is the incidence matrix reporting a vector of $1 \mathrm{~s}$ and the number of copies of the $K$ allele $(0,1$, or 2 for the genotypes $A A, A K$, and $K K$, respectively), and $\mathbf{Z}$ is the incidence matrix for the animal additive polygenic effect.

Statistical analyses were implemented in a Bayesian framework using Gibbs sampling. For all models, priors for additive genetic effects $a$ were multivariate normal $a \sim N\left(0, \mathbf{A} \sigma_{a}^{2}\right)$, where $\mathbf{A}$ is the numerator relationship matrix, whereas priors for residual $\left(\sigma_{e}^{2}\right)$ and additive polygenic variance $\left(\sigma_{a}^{2}\right)$ followed an inverted chi-squared distribution invChisq $(\nu, S)$, where $v$ is the degrees of freedom and $\mathrm{S}$ is the scale. Whereas $\nu$ was considered equal to 6 for all priors, $\mathrm{S}$ was chosen according to the expectation of variances for the specific trait. Expectations of additive polygenic and residual variance were inferred running a simplified model without marker effect using a noninformative prior. Therefore, given $\mathrm{V}_{\mathrm{a}}$ and $\mathrm{V}_{\mathrm{e}}$ as expectation of additive polygenic and residual variance, respectively, additive polygenic effect variance had scale $S_{a}=V_{a}(\nu-2)$, whereas residual variance had scale $S_{e}=V_{e}(\nu-2)$. Average allele substitution effect and population mean were sampled from a flat prior. Gibbs chains were run for 250,000 iterations with 
50,000 iterations as burn-in and thinning every 20 iterations. Convergence was assessed by visual inspection of trace plots. Analyses were performed using the package MCMCglmm (Hadfield, 2010) implemented in R (www.R-project.org). Posterior mean and 95\% highest probability density intervals (HPD95\%) were used as estimate and error of the average allele substitution effect, respectively.

The frequencies of the $A A, K A$, and $K K$ genotypes were $59.6,32.1$, and $8.3 \%$, respectively, and the minor allele frequency ( $K$ variant) was $24.7 \%$. The DGAT1 gene locus deviated from Hardy-Weinberg equilibrium (chi-squared $=5.26 ; P=0.022$ ), with a deficit of heterozygotes (4.8\% less than the expected value) in favor of both $A A$ and $K K$ genotypes. Deviation from HardyWeinberg equilibrium could be due to the sampling of genotyped bulls or to an indirect effect of selection for production traits. The relatively low frequency of the $K$ allele observed in this study is in agreement with the value of 0.254 reported by Scotti et al. (2010) in 116 Italian Holstein-Friesian animals (43 sires and 73 cows). Nevertheless, $K$ allele frequency varies greatly in different Holstein populations, possibly as a result of different past breeding objectives regarding milk production traits in different countries. For instance, unlike the result of the present study, greater frequencies of the lysine variant have been reported in Greece (Oikonomou et al., 2009) and New Zealand (Spelman et al., 2002), with values of 0.62 and 0.60 , respectively. German (Bennewitz et al., 2004; Kaupe et al., 2007), UK (Banos et al., 2008) and Polish (Nowacka-Woszuk et al., 2008) Holsteins showed very similar $K$ allele frequency, ranging from 0.53 to 0.55 , and US (Barbosa da Silva et al., 2010) and Dutch (Bovenhuis et al., 2015) Holsteins reported a minor allele frequency of 0.40 . Slightly lower frequencies were reported in a French study (0.37; Gautier et al., 2007) and in an Irish study (0.32; Berry et al., 2010). Low to intermediate frequencies, ranging from 0.13 to 0.29 , have been reported in Holstein populations from Sweden (Näslund et al., 2008), Brazil (Lacorte et al., 2006), Czech Republic (Manga and Ř́ha, 2011), Israel (Weller et al., 2003), and China (Mao et al., 2012). The population structure at this important polymorphic site has also been analyzed in other cattle breeds. Evaluation of the DGAT1 mutation in Italian dairy and dual-purpose breeds was performed by Scotti et al. (2010), identifying the lysine variant in Reggiana with a frequency of 0.172 and with very low frequency $(<0.01)$ in Simmental, Valdostana Red Pied, and Rendena breeds. Only homozygous $A A$ were found in Italian Brown and Modenese breeds. However, the K232A polymorphism was present in the Italian Brown cattle population analyzed by Conte et al. (2010), with a frequency of 0.02 .
Descriptive statistics of milk yield, composition, SCS, and coagulation properties (Table 1) were mostly in agreement with findings of previous studies conducted on Italian Holsteins (Cassandro et al., 2008; Tiezzi et al., 2013; Viale et al., 2017), with small differences probably related to the sampling. Candidate-gene association analysis allowed the estimation of the effect of K232A polymorphism of DGAT1 on the investigated traits through the use of the $\mathrm{dEBV}$ of the individuals. The allelic substitution ( $A$ to $K$ allele) effects for the DGAT1 mutation on all considered traits are reported in Table 1. For milk, fat, protein, and casein yields, the average allele substitution effects were $-0.787,0.242$, 0.031 , and $0.021 \mathrm{~kg} / \mathrm{d}$, respectively, and only fat yield had an HPD95\% that did not include zero, thus suggesting that the $K$ allele was significantly associated with increased fat yield. Considering milk composition traits, the estimated average effects of allele substitution were $0.558,0.099,0.074,-0.284$, and $-14.31 \%$ for fat, protein, casein, casein:protein ratio, and protein:fat ratio, respectively, with $\mathrm{HPD} 95 \%$ that included zero only in the case of casein:protein ratio (Table 1), meaning that the $K$ allele was significantly associated with greater fat, protein, and casein percentages and with reduced protein:fat ratio. Banos et al. (2008) reported a value of -0.79 for milk yield in UK dairy cows, and Näslund et al. (2008) showed values of $-0.61,0.11$, and 0.01 for milk, fat, and protein yields, respectively, in Swedish Holstein cattle. Similar values were reported by Bennewitz et al. (2004) in German Holstein cattle. These results confirmed the effect of the allele substitution in different European dairy cattle populations (also using different samples and methods of estimation). Effects of the DGAT1 polymorphism on milk production traits were also reported by Bovenhuis et al. (2015), who observed the $K$ allele to be associated with lower milk, protein, and lactose yields and greater fat yield and fat, protein, and lactose percentages. Furthermore, an effect of DGAT1 on synthesis and composition of fatty acids was observed by Conte et al. (2010) and Bovenhuis et al. (2016), whereas a genotype effect on milk total polar lipid content and on milk fat globule membrane composition due to the DGAT1 K232A polymorphism was reported by Argov-Argaman et al. (2013). The average allele substitution effect for the DGAT1 mutation with regards to SCS was 0.027 (Table 1), but the association was not statistically significant. Among the studies that investigated the relationship between the K232A polymorphism and somatic cells, Barbosa da Silva et al. (2010) reported a negative value of -0.048 , whereas no association was observed by Kaupe et al. (2007), Näslund et al. (2008), Berry et al. (2010), Mao et al. (2012), and Bovenhuis et al. (2015) in German, Swedish, Irish, Chinese, and Dutch Holsteins, respectively. 
Table 1. Descriptive statistics $\left(\mathrm{n}=1,309,884^{1}\right)$ of milk traits, mean and SD of the reliability of deregressed breeding values (dEBV), and estimates $^{2}$ of the average allele substitution effect $(\alpha ; A$ to $K$ allele) for the diacylglycerol acyltransferase $(D G A T 1)$ mutation on bovine chromosome 14

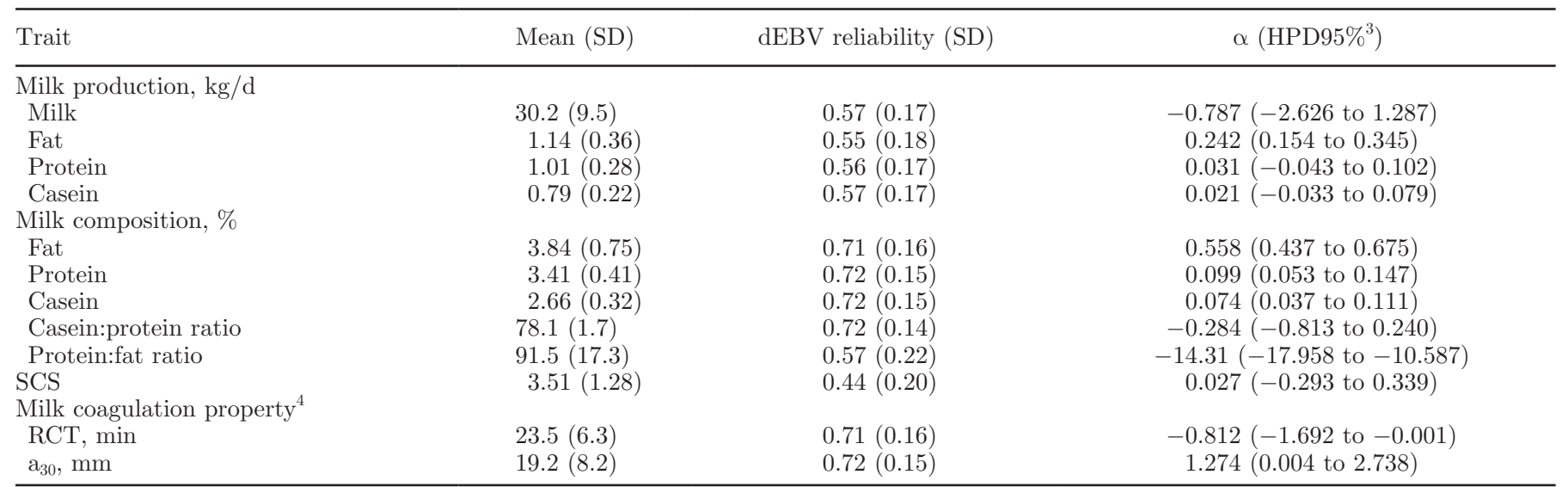

${ }^{1} \mathrm{n}=1,142,633$ for SCS.

${ }^{2}$ Estimates are the means (lower and upper bound of the 95\% highest posterior density region, HPD95\%) of the marginal posterior distributions. ${ }^{3} 95 \%$ highest probability density interval.

${ }^{4} \mathrm{RCT}=$ rennet coagulation time; $\mathrm{a}_{30}=$ curd firmness $30 \mathrm{~min}$ after rennet addition to milk.

For MCP, the estimated average effects of allele substitution for the DGAT1 mutation on bovine chromosome 14 were -0.812 min for RCT (HPD95\%, -1.692 to $-0.001 \mathrm{~min}$ ) and $1.274 \mathrm{~mm}$ for $\mathrm{a}_{30}$ (HPD95\%, 0.004 to $2.738 \mathrm{~mm}$; Table 1). To our knowledge, this is the first study that has estimated the effect of the K232A polymorphism of DGAT1 on MCP. Our findings suggested an association of DGAT1 mutation with shorter RCT and greater curd firmness. A reasonable explanation for the effect of DGAT1 mutation on $\mathrm{a}_{30}$ could arise from the relationship between the polymorphism and milk fat and, consequently, the relationship between milk fat globules and rennet-induced gel formation. Indeed, the $K K$ genotype was found to be associated with larger fat globules and variation in their membrane composition (Argov-Argaman et al., 2013). Interestingly, it has been demonstrated that composition of fat globule surface (Lopez and Dufour, 2001) and fat globule size (Michalski et al., 2003) affect the rheological and structural properties of the coagulum. In particular, curds with small fat globules were less firm than curds with large fat globules and underwent greater proteolysis during ripening (Michalski et al., 2003).

In conclusion, results from the present study confirmed the effects of the diallelic DGAT1 polymorphism K232A described by Grisart et al. (2002) and Winter et al. (2002) on milk production traits. In addition, we observed that the K232A mutation favorably affected the coagulation ability of milk in Italian Holsteins, whereas it did not affect SCS. These findings provide strong arguments for further research in gene-assisted selection in the Italian Holstein population.

\section{ACKNOWLEDGMENTS}

This research was supported by the University of Padova (Italy) as part of the project "Assessing the genomic architecture of milk technological traits in Italian Holstein-Friesian cattle breed" (CPDR140215/14). The authors thank Intermizoo S.p.A. (Padova, Italy) for providing semen samples, the Italian Holstein Association (Cremona, Italy) for pedigree information, and the Breeders Association of Veneto Region (Vicenza, Italy) for phenotypic data. The authors gratefully acknowledge Denis Pretto and Fabio Maretto (University of Padova, Italy) for technical support and laboratory analyses.

\section{REFERENCES}

Argov-Argaman, N., K. Mida, B.-C. Cohen, M. Visker, and K. Hettinga. 2013. Milk fat content and DGAT1 genotype determine lipid composition of the milk fat globule membrane. PLoS One 8:e68707.

Banos, G., J. A. Woolliams, B. W. Woodward, A. B. Forbes, and M. P. Coffey. 2008. Impact of single nucleotide polymorphisms in leptin, leptin receptor, growth hormone receptor, and diacylglycerol acyltransferase (DGAT1) gene loci on milk production, feed, and body energy traits of UK dairy cows. J. Dairy Sci. 91:3190-3200.

Barbosa da Silva, M. V. G., T. S. Sonstegard, R. M. Thallman, E. E. Connor, R. D. Schnabel, and C. P. Van Tassell. 2010. Characterization of DGAT1 allelic effects in a sample of North American Holstein cattle. Anim. Biotechnol. 21:88-99.

Bennewitz, J., N. Reinsch, S. Paul, C. Looft, B. Kaupe, C. Weimann, G. Erhardt, G. Thaller, C. Kuhn, M. Schwerin, H. Thomsen, F. Reinhardt, R. Reents, and E. Kalm. 2004. The DGAT1 K232A mutation is not solely responsible for the milk production quantitative trait locus on the bovine chromosome 14. J. Dairy Sci. $87: 431-442$.

Berry, D. P., D. Howard, S. O'Boyle, S. Waters, J. F. Kearney, and M. McCabe. 2010. Associations between the K232A polymorphism 
in the diacylglycerol-O-transferase 1 (DGAT1) gene and performance in Irish Holstein-Friesian dairy cattle. Ir. J. Agric. Food Res. 49:1-9.

Bovenhuis, H., M. H. P. W. Visker, N. A. Poulsen, J. Sehested, H. J. F. van Valenberg, J. A. M. van Arendonk, L. B. Larsen, and A. J. Buitenhuis. 2016. Effect of the diacylglycerol o-acyltransferase 1 (DGAT1) K232A polymorphism on fatty acid, protein, and mineral composition of dairy cattle milk. J. Dairy Sci. 99:3113-3123.

Bovenhuis, H., M. H. P. W. Visker, H. J. F. van Valenberg, A. J. Buitenhuis, and J. A. M. van Arendonk. 2015. Effects of the DGAT1 polymorphism on test-day milk production traits throughout lactation. J. Dairy Sci. 98:6572-6582.

Cassandro, M., A. Comin, M. Ojala, R. Dal Zotto, M. De Marchi, L. Gallo, P. Carnier, and G. Bittante. 2008. Genetic parameters of milk coagulation properties and their relationships with milk yield and quality traits in Italian Holstein cows. J. Dairy Sci. 91:371376.

Conte, G., M. Mele, S. Chessa, B. Castiglioni, A. Serra, G. Pagnacco, and P. Secchiari. 2010. Diacylglycerol acyltransferase 1, stearoylCoA desaturase 1 , and sterol regulatory element binding protein 1 gene polymorphisms and milk fatty acid composition in Italian Brown cattle. J. Dairy Sci. 93:753-763.

De Marchi, M., M. Penasa, F. Tiezzi, V. Toffanin, and M. Cassandro. 2012. Prediction of milk coagulation properties by Fourier transform mid-infrared spectroscopy (FTMIR) for genetic purposes, herd management and dairy profitability. In 38th International Committee for Animal Recording Meeting, Cork, Ireland. Accessed Jan. 15, 2018. http://www.icar.org/Cork_2012/ Manuscripts/Published/Cassandro.pdf.

Garrick, D. J., J. F. Taylor, and R. L. Fernando. 2009. Deregressing estimated breeding values and weighting information for genomic regression analyses. Genet. Sel. Evol. 41:55.

Gautier, M., A. Capitan, S. Fritz, A. Eggen, D. Boichard, and T. Druet. 2007. Characterization of the DGAT1 K232A and variable number of tandem repeat polymorphisms in French dairy cattle. J. Dairy Sci. 90:2980-2988.

Graffelman, J. 2015. Exploring diallelic genetic markers: The HardyWeinberg package. J. Stat. Softw. 64(3):1-23.

Grisart, B., W. Coppieters, F. Farnir, L. Karim, C. Ford, P. Berzi, N. Cambisano, M. Mni, S. Reid, P. Simon, R. Spelman, M. Georges, and R. Snell. 2002. Positional candidate cloning of a QTL in dairy cattle: Identification of a missense mutation in the bovine DGAT1 gene with major effect on milk yield and composition. Genome Res. 12:222-231.

Grisart, B., F. Farnir, L. Karim, N. Cambisano, J. J. Kim, A. Kvasz, M. Mni, P. Simon, J. M. Frere, W. Coppieters, and M. Georges. 2004. Genetic and functional confirmation of the causality of the DGAT1 K232A quantitative trait nucleotide in affecting milk yield and composition. Proc. Natl. Acad. Sci. USA 101:2398-2403.

Hadfield, J. D. 2010. MCMC methods for multi-response generalized linear mixed models: The MCMCglmm R Package. J. Stat. Softw. $33(2): 1-22$

Kaupe, B., H. Brandt, E.-M. Prinzenberg, and G. Erhardt. 2007. Joint analysis of the influence of CYP11B1 and DGAT1 genetic variation on milk production, somatic cell score, conformation, reproduction, and productive lifespan in German Holstein cattle. J. Anim. Sci. 85:11-21.

Kühn, C., G. Thaller, A. Winter, O. R. Bininda-Emonds, B. Kaupe, G. Erhardt, J. Bennewitz, M. Schwerin, and R. Fries. 2004. Evidence for multiple alleles at the DGAT1 locus better explains a quantitative trait locus with major effect on milk fat content in cattle. Genetics 167:1873-1881.

Lacorte, G. A., M. A. Machado, M. L. Martinez, A. L. Campos, R. P. Maciel, R. S. Verneque, R. L. Teodoro, M. G. C. D. Peixoto, M. R. S. Carvalho, and C. G. Fonseca. 2006. DGAT1 K232A polymorphism in Brazilian cattle breeds. Genet. Mol. Res. 5:475-482.

Lopez, C., and E. Dufour. 2001. The composition of the milk fat globule surface alters the structural characteristics of the coagulum. J. Colloid Interface Sci. 233:241-249.
Manga, I., and H. Ř́ha. 2011. The DGAT1 gene K232A mutation is associated with milk fat content, milk yield and milk somatic cell count in cattle. Arch. Tierzucht 54:257-263.

Mao, Y. J., R. J. Chen, L. L. Chang, Y. Chen, D. J. Ji, X. X. Wu, X. K. Shi, H. T. Wu, M. R. Zhang, Z. P. Yang, S. Könik, and L. G. Yang. 2012. Effects of SCD1- and DGAT1-genes on production traits of Chinese Holstein cows located in the Delta Region of Yangtze River. Livest. Sci. 145:280-286.

Michalski, M. C., J. Y. Gassi, M. H. Famelart, N. Leconte, B. Camier, F. Michel, and V. Briard. 2003. The size of native milk fat globules affects physico-chemical and sensory properties of Camembert cheese. Lait 83:131-143.

Miglior, F., A. Fleming, F. Malchiodi, L. F. Brito, P. Martin, and C. F. Baes. 2017. A 100-year review: Identification and genetic selection of economically important traits in dairy cattle. J. Dairy Sci. 100:10251-10271.

Näslund, J., W. F. Fikse, G. R. Pielberg, and A. Lunden. 2008. Frequency and effect of the bovine acyl-CoA:diacylglycerol acyltransferase 1 (DGAT1) K232A polymorphism in Swedish dairy cattle. J. Dairy Sci. 91:2127-2134.

Nowacka-Woszuk, J., A. Noskowiak, T. Strabel, T. Jankowski, and M. Świtoński. 2008. An effect of the DGAT1 gene polymorphism on breeding value of Polish Holstein-Friesian sires. Anim. Sci. Pap. Rep. 26:17-23.

Oikonomou, G., K. Angelopoulou, G. Arsenos, D. Zygoyiannis, and G. Banos. 2009. The effects of polymorphisms in the DGAT1, leptin and growth hormone receptor gene loci on body energy, blood metabolic and reproductive traits of Holstein cows. Anim. Genet. 40:10-17.

Pretto, D., M. De Marchi, M. Penasa, and M. Cassandro. 2013. Effect of milk composition and coagulation traits on Grana Padano cheese yield under field conditions. J. Dairy Res. 80:1-5.

Scotti, E., L. Fontanesi, F. Schiavini, V. La Mattina, A. Bagnato, and V. Russo. 2010. DGAT1 p.K232A polymorphism in dairy and dual purpose Italian cattle breeds. Ital. J. Anim. Sci. 9:e16.

Spelman, R. J., C. A. Ford, P. McElhinney, G. C. Gregory, and R. G. Snell. 2002. Characterization of the DGAT1 gene in the New Zealand dairy population. J. Dairy Sci. 85:3514-3517.

Thaller, G., C. Kühn, A. Winter, G. Ewald, O. Bellmann, J. Wegner, H. Zuhlke, and R. Fries. 2003. DGAT1, a new positional and functional candidate gene for intramuscular fat deposition in cattle. Anim. Genet. 34:354-357.

Tiezzi, F., D. Pretto, M. De Marchi, M. Penasa, and M. Cassandro. 2013. Heritability and repeatability of milk coagulation properties predicted by mid-infrared spectroscopy during routine data recording, and their relationships with milk yield and quality traits. Animal 7:1592-1599.

Viale, E., F. Tiezzi, F. Maretto, M. De Marchi, M. Penasa, and M. Cassandro. 2017. Association of candidate gene polymorphisms with milk technological traits, yield, composition, and somatic cell score in Italian Holstein-Friesian sires. J. Dairy Sci. 100:7271-7281.

Visentin, G., M. De Marchi, D. P. Berry, A. McDermott, M. A. Fenelon, M. Penasa, and S. McParland. 2017. Factors associated with milk processing characteristics predicted by mid-infrared spectroscopy in a large database of dairy cows. J. Dairy Sci. 100:3293-3304.

Weller, J. I., M. Golik, E. Seroussi, E. Ezra, and M. Ron. 2003. Population-wide analysis of a QTL affecting milk-fat production in the Israeli Holstein population. J. Dairy Sci. 86:2219-2227.

Wiggans, G. R., and G. E. Shook. 1987. A lactation measure of somatic cell count. J. Dairy Sci. 70:2666-2672.

Winter, A., W. Krämer, F. A. O. Werner, S. Kollers, S. Kata, G. Durstewitz, J. Buitkamp, J. E. Womack, G. Thaller, and R. Fries. 2002. Association of a lysine-232/alanine polymorphism in a bovine gene encoding acyl-CoA:diacylglycerol acyltransferase (DGAT1) with variation at a quantitative trait locus for milk fat content. Proc. Natl. Acad. Sci. USA 99:9300-9305. 